\title{
Public Health and Community Medicine
}

Open Access

RESEARCH ARTICLE

\section{The Ethics of Physician-Assisted Suicides (PAS) through Kantian, Aristotelian, Jewish, and Christian Liberationist Frameworks}

\section{Cameron J Sabet}

University of Pennsylvania, Alexandria, USA

*Corresponding author: Cameron J Sabet, University of Pennsylvania, 5130 Duke Street Suite 9, Alexandria, VA 22312, USA

The American Academy of Hospice and Palliative Medicine (AAHPM) defines the term physician-assisted suicide "as a physician providing, at the patient's request, a prescription for a lethal dose of medication that the patient can self-administer by ingestion, with the explicit intention of ending life". Although physicianassisted suicide has historically not been within the domains of standard medical practice, in recent years it has emerged as both an "explicit and covert practice across various legal jurisdictions in the United States" [1]. To make matters even more complicated, the official opinion of the American Medical Association (AMA) is to relinquish the burden of responsibility by leaving these issues entirely up to the discretion of the medical practitioner: "Preserving opportunity for physicians to act (or to refrain from acting) in accordance with the dictates of conscience in their professional practice is important for preserving the integrity of the medical profession as well as the integrity of the individual physician, on which patients and the public rely. Thus, physicians should have considerable latitude to practice in accord with well-considered, deeply held beliefs that are central to their self-identities" [2]. In short, to argue that it is completely within the scope of a given healthcare provider's set of options to make the decision to finish a patient's life prematurely would be in accordance with the official opinion of the American Medical Association. Given that the American Medical Association offered the decision up for moral discussion, this paper is going to advance the position that, if a physician consults the patient's family and their own moral sensibilities before making the decision to end the life of a patient in a vegetative state, the patient has not and cannot provide an official opinion on the matter, or the patient's continued requirement of staying on life support is a crippling financial burden on a low-income family, or if the patient is experiencing intolerable pain, then it is well within the scope of not necessarily the physician's personal inclinations, but rather duty, to end the patient's life. This article will wed modern perspectives with the seminal works of philosophy we explored in class that first sparked this debate, including Kant's categorical imperative, Aristotle's Nicomachean Ethics, Jewish ethics, and Christian liberationist ethics. This paper will then build from these cultural frameworks to advance a more practical stance on this public health issue: That physician-assisted suicides are not just moral, but absolutely imperative in certain circumstances.

Immanuel Kant (1724-1804) was a Prussian philosopher who was a seminal figure in the development of the field of Kantian ethics. This brand of ethics advances a concept known as the categorical imperative, the first formulation of which-the Universality Principleproposes that one should "Act only according to that maxim which you can at the same time will that it should become a universal law without contradiction" [3]. In a sense, one should act in such a way that such an action could become a universal law for all rational beings, and that there should be no exceptions for anyone. In the

Citation: Sabet CJ (2021) The Ethics of Physician-Assisted Suicides (PAS) through Kantian, Aristotelian, Jewish, and Christian Liberationist Frameworks. Int Arch Public Health Community Med 5:064. doi. org/10.23937/2643-4512/1710064

Accepted: October 04, 2021; Published: October 06, 2021

Copyright: (C) 2021 Sabet CJ. This is an open-access article distributed under the terms of the Creative Commons Attribution License, which permits unrestricted use, distribution, and reproduction in any medium, provided the original author and source are credited. 
abstract, this would mean that one cannot steal, since it was a universal law for everyone to steal, no one would be able to enjoy proprietary rights, and society would not function properly due to a lack of trust.

Applying this theory to the notion of physicianassisted suicide, it is entirely up to the physician whether or not they would provide their doctor permission to pull the plug on them if they were in a vegetative state, since there is no touchstone specific enough to guide the doctor in any highly specific and nuanced situation. The decision to save or kill is highly subjective, and various cultural traditions would likely bias the doctor one way or another. Such biases do not always align with the views of their patient or their patient's family. Even if this critique rooted in context did not kneecap Kant's First Formulation, the Universality Principle is inherently contradictory. For example, would it be morally permissible to lie about the culpability of someone who is guilty to save them from an unnecessarily harsh punishment? In Kant's view, this would be morally wrong, since human civilizations require at least some trust to function properly; if no one ever told the truth in a situation where trust was needed to create spaces of great social stability to encourage potential investments and technological progress, then this given society would collapse. Therefore, Kant's Universality Principle does not allow for nuance and would not serve as a proper defense in favor of or against physicianassisted suicide.

Applying this rebuttal of the application of the Universality Principle to matters in real life, such as in the case of physician-assisted suicide, means that a) If the doctor pulls the plug on any given patient, anyone should be allowed to end the life of anyone who they deem not to be worthy of life, or b) If the doctor keeps the patient on the line, everyone deserves to live without the freedom of others trampling upon them. The latter's moral standard would even require all prisoners to be freed and for no country to wage wars on any grounds, since the military forces would be taking the lives of others and restricting the freedom of soldiers through sustained injuries, emotional trauma, and various forms of bereavement suffered hundreds of miles from the front lines. However, the nature of human behavior demands that prisons be built and wars be fought to protect and preserve order in the world. There is another issue with the application of the Universality Principle on such slippery ethical terrain, in that the level of universality is contingent upon the judgment of the person applying said principle. For example, would the application of part (a) Require doctors to go around and put everyone in a vegetative state exactly like that patient, and then pull the plug on everyone just as they did to that one patient? Or, would applying part (a) Require everyone to kill everyone else by any means necessary? Either way, neither could happen, since this is such a rare occurrence that if every doctor ended the life of every patient every time this exact situation arose, there would be only one situation in which this would happen, and the doctor would ironically be free from any and all ethical obligations arising from the Universality Principle. However, if the doctor extends the situation to include any deaths, different pains are associated with different deaths, other deaths would not be precisely identical to pulling the plug on a patient that is barely conscious. Therefore, the difficulty of the Universality Principle lies in the limits of its application; no two situations are identical, and no two human beings make perfectly rational decisions, such that the judgment of one can serve in place of the other. This line of reasoning is perhaps best encapsulated in a situation where a logician orders two perfectly identical hot dogs from a waiter (who happens to be another logician), and the waiter logician comes back with a single hot dog. Only one place, one time, one exact molecular composition matches the first hot dog.

Bringing this argument of identical identities back to Kantian ethics, since no two situations are perfectly identical, the self-contradictory Universality Principle cannot serve as a satisfactory touchstone by which one can measure the moral value of a given decision on the continued survival or death of a patient in a vegetative state. Though Kant's first formulation of his categorical imperative is a refreshing thought-experiment derived partially from the Golden Rule that famously advises treating others the way we would like to be treated, it is not practically applicable to highly specific and nuanced situations, and therefore translates poorly to real-world situations.

Another proposed approach to this modern public health ethical dilemma is to apply the principles found in Aristotle's (384-322 BC) Nicomachean Ethics, wherein one must achieve eudaimonia by doing what one believes is the correct path. However, this ignores the issue of corrupting influences in the path toward moral development, such as an education that teaches one never to critique one's own education, leading to an ethical blind spot that can obscure otherwise incorrigible behavior from one's own judgment. Therefore, even if a doctor's internal disposition and motives are pure, a situation can be so thick with nuance that one could argue rationally that either pulling the plug or not would be the correct moral choice, in their own subjective viewpoint, and that they should feel good about their choice as long as it equates with their personal viewpoints. Therefore, the application of one's personal moral judgments through Aristotle's Nicomachean Ethics is not helpful for advocating the position that physician-assisted suicides are imperative in certain cases, and the practical viability of this philosophical approach is refuted [4].

However, applying both Kant's aforementioned Universality Principle in concert with liberationist ethics 
finally allows us to gain ground, since the issue of class tips the scales of the argument. Christianity birthed liberationist ethics, a concept where God exercises a preferential option for the meek, poor, and lowly in his judgments. In fighting for the poor and oppressed to seek justice, one catalyzes social improvement and can rest easy knowing that God will praise them for being a servant of the people. For families that cannot afford to keep paying exorbitant medical bills and do not have access to reputable and cheaper homeopathic care to at least attempt to keep the vegetative patient alive without saddling such burdens, it is imperative that a physician pull the plug. This would also be employing a utilitarian approach, since the net burden on an unconscious, immobile, or unproductive patient would be less than the financial burden on the patient's conscious, mobile, and potentially productive relatives extolled by the healthcare system's expensive medical bills. However, this option should only be imperative if and only if a family cannot afford to continue sustaining the patient financially without entering into crippling debt, and if the patient is no longer conscious and cannot feel the pain and agony of dying anymore.

Before this paper moves onto Kant's Second Formulation, it is important to explore potential cultural biases ingrained in the doctor's mind and, more importantly, the traditions surrounding the practice of medicine. Alasdair Macintyre (1929) was a ScottishAmerican moral relativist who emphasized how morality has a narrative context, that history matters for our ethical understanding of the world, and that morality is grounded in tradition. To begin, modern medicine differentiates between "voluntary (conducted with the consent of the patient), non-voluntary (conducted when the consent of the patient is unavailable), or involuntary (conducted against the will of the patient) consent" [5]. The non-voluntary case is justified by the American Medical Association, as earlier mentioned, and leaves it up to the sole discretion of the healthcare provider when a Do Not Resuscitate card is unavailable or patient consent is unattainable. The involuntary case occurs when there are not enough resources available, either on behalf of the care provider or the patient's family finances. However, the cultural component of this essay hinges upon the first voluntary component, whereby the patient may petition to end a life of pain and suffering prematurely, with the help of the care provider. This is where Alasdair's narrative morality comes in. The Hippocratic Oath, one of the most famous texts of the ancient Greek civilization, writes that "And in honor of the knowledge I have received from my teachers, I swear to care for anyone who suffers, prince or slave" [6]. At a glance, this long standing piece of cultural tradition suggests that one should always resort to palliative care or hospice over pulling the plug, either voluntarily, involuntarily, or non-voluntarily. However, if one analyzes further, perhaps "Carrying for anyone who suffers, prince or slave" could also mean putting a patient out of misery via euthanasia. If we choose to apply Kant's aforementioned First Formulation loosely here-the rusty compass of moral philosophy that takes you in circles if you look at it long enoughit is actually imperative that a physician follow through with euthanasia, since the world could run nicely with perfect altruism.

Even if a patient's family can afford the cost of continued palliative treatment, Kant's Second Formulation of his Categorical Imperative would only apply if the patient in a vegetative state was still able to move their eyes and thereby signify to others that they are making rational and coherent decisions. If this patient is able to do that, the bare minimum to be considered a rational and competent decision-maker, then, according to Kant's Second Formulation, one should "act in such a way that you always treat humanity, whether in your own person or in the person of any other, never simply as a means, but always at the same time as an end" [3]. In this sense, the aforementioned liberationist ethics and utilitarian hybrid approach clashes with Kant's ethical approach here, since the patient should not be unhooked from life support just because their family is lacking the financial resources to keep the patient alive. The patient is a victim, and we should take their side. According to James Rachels in the Morality of Euthanasia, if "A person is leading a miserable life full of more unhappiness than happiness but does not want to die, then this person thinks that a miserable life is better than none at all" [7]. Therefore, liberationist ethics would require doctors to deliver the victim either from an unwanted death or to a wanted death, regardless of our personal views on the matter. This would hold true even if any members of that family would rather die in the patient's situation or even in members of the medical team-including the doctorbelieve otherwise. This perspective clashes with Kant's Categorical Imperative, where you should treat others the way you would want to be treated. Instead, it merely states that you should treat others the way the other person would like to be treated. This approach could even force the healthcare provider to continue caring for a patient even if the patient cannot signify any desires to be alive or not if a "Do Not Resuscitate" card cannot be found, since our absolute moral worth forbids us from "manipulating other autonomous agents for our own benefit" according to Kant's Categorical Imperative [8]. In this sense, "our benefit" would mean the patient's family and the bills they would be spared. Practically speaking, however, this is an unrealistic precedent. In a sense, healthcare providers cannot put themselves in others' shoes primarily because they have wholly different upbringings and behavioral inclinations. Once again, this concept of sameness comes into play, where there do not exist ceteris-paribus logical games in reallife; only fractals of nuance and subjectivity. Even if your 
intention is "pure" and you believe you are truly thinking in the patient's shoes, your cultural and academic education biases you one way or another. This makes everyone unfit to make the decision. As an example of a teaching that renders a physician unfit to make such decisions, uncritical backgrounds that teach never to kill, as famously quoted in the Old Testament, can raise an impressionable child into a biased medical practitioner that cannot obey the patient's will. This is because the Commandments do not require any moral disposition to follow; they are merely a set of exhibited behaviors that one should not perform at any time. If it is morally imperative for the physician to pull the plug based on liberationist ethics, for example, how can we hold such physicians accountable if their actions are never of their own volition, but are a product of their circumstances or religious upbringing? Should all doctors take an oath that they will act in accordance with certain universally agreed-upon principles in specific circumstances, and if their religion interferes with their ability to do so, that they cannot be a licensed medical practitioner? Is it moral, or even wise, to have a universal medical code that specifies exactly when a medical practitioner is legally obligated to pull the plug on the patient? Should the American Medical Association start mechanizing clinical practice and ignoring the individual opinions of the care providers working under it?

There is yet another layer of philosophical machinery underlying all of the above arguments: What does it even mean to be human? If a patient is in an unconscious state whereby they are able to breathe and pump their own blood, but not to act on their own volition, are they no more human than the bed upon which their body lays? After all, once biochemical reactions stop within a human and the blood stops pumping, they are immediately referred to as a body, not a person. What part of a human life defines a human? This husk of what a human once was, is not unalike an abandoned house. It may have once been a home where someone lived and made memories. But an unabandoned abode is just a house. Once the lights go off and the occupants leave, even if the air conditioning is still running, it is just another structure in this massive world. Similarly, once the person stops being conscious, they have no physical agency in this world, and they become merely a body. At this point, a family with informed consent could be morally correct in deciding to pull the plug, even if they are not poor and are not the defined beneficiaries of liberationist ethics. At that point, the patient's body is merely a foreclosed house with the lights still on and the air conditioning still running. Especially if a patient cannot consent at a particular moment or did not inform anyone of their wishes before entering their vegetative state through a Do Not Resuscitate order, such patients should be free to the whims of the healthcare provider's judgment like the American Medical Association states.

A few counter arguments against the practice of euthanasia were presented in our Religion and Morality course through Cundiff's Traditional Arguments against Euthanasia. One argument presented was how "a law legalizing euthanasia might well be abused, with some person's life being ended against his or her consent for a motive other than mercy" [9]. However, physicians are free to do anything, especially since patients have no idea what they are being prescribed and are really submitting themselves to the judgment of their medical practitioner. Physicians can abuse this trust, for example, by over-prescribing Botox (an extremely expensive medication) to their patients with chronic migraines or even diluting such pricey medications with saline solution in the back of the clinic without the patient nor even insurance companies ever noticing. Therefore, the potential for malpractice is omnipresent and should not be grounds for outlawing a procedure as important as euthanasia. Furthermore, Cundiff proposes an argument that economic vulnerabilities could pressure "frail, disabled elderly people who are financial and emotional burdens on their families... to ask for euthanasia to spare their families from further suffering" [9]. However, this counterargument against utilitarianism can be said for just about any modern health privilege that can be bought, such as food deserts, where people in less affluent communities do not have access to the same "healthful and affordable food" as more socioeconomically advantaged communities which leads to a higher incidence of related conditions like obesity, diabetes, and various cardiovascular diseases [10]. The argument that euthanasia is a net positive in certain circumstances is not seeking to justify the injustices of our current health landscape. It is merely stating that the issue of socioeconomic inequality is not unique to this particular debate and extends to just about every treatment, privilege, or food option available to consumers in the United States today. Therefore, it is not connected with the morality of the procedure itself. After all, in 2018 alone, payments to our nation's private healthcare industry were responsible for one-third (34\%) of the total payments to the health industry, and two-thirds of Americans rely on private health insurance to cover them. To compound this problem, 27.5 million people remain uninsured (or around $8.5 \%$ ) across the United States [11]. This means that those tens of millions of people would likely decline surgeries or preventative treatments, even if it would save their lives, simply because our current healthcare system is so costly. It is not a valid argument to introduce any procedure, whether moral or immoral, into an immoral system and declare it immoral simply due to the environment in which it was introduced. The statement that euthanasia would force the poor to relinquish treatments faster may be true, but the argument stemming from it-that this invalidates any advances in medical protocol because the rich would get treated faster and better-is not a valid justification 
for stopping all treatments simply because the our modern healthcare industry will favor those with wealth over those without.

Whether or not it is morally acceptable to practice euthanasia is a complex moral debate that straddles issues of social policy, economic inequality, morality, existentialism, and religious philosophy. It is imperative that aspiring physicians like myself take the time to explore these phenomena and understand the contours of each position in this debate through the likes of Kant, Aristotle, Jewish ethics, and liberationist ethics. After all, a physician may one day encounter a patient whose family insists they have a Do Not Resuscitate order, but cannot produce it in time to stop the healthcare team from stepping in and having to decide for themselves whether or not to assist the patient. Applying blanket philosophies in such circumstances, like Kant's Categorical Imperative, can never hold in real life because every situation is complex and unique. Therefore, this leaves us with one answer: Euthanasia is imperative in certain situations, and outlawing the practice on the grounds that it would exacerbate existing socioeconomic inequalities would require outlawing every other expensive yet life saving procedure available to the general public.

\section{References}

1. American Academy of Hospice and Palliative Medicine (2016) Statement on Physician-Assisted Dying.

2. American Medical Association (2021) Physician-Assisted Suicide.

3. Kant I (1785) Fundamental Principles of the Metaphysics of Morals.

4. Aristotle, Ross WD, Brown L (2009) The Nicomachean Ethics. Oxford University Press.

5. Asthana S, Francis V (2021) Why I decided to provide assisted dying: It is truly patient centred care. The BMJ 364 : 1412.

6. Hippocrates of Kos. Hippocratic Oath, 500 BC.

7. Rachels James (1986) The Morality of Euthanasia. Euthanasia and a Modest Proposal, 252-257.

8. Hank G (2016) Kant \& Categorical Imperatives: Crash Course Philosophy \#35.

9. Cundiff David E (1992) Euthanasia is not the answer: A hospice physician's view. Humana Press.

10. Marengo K (2020) Food Deserts: Definition, Effects, and Solutions. Medical News Today, Medi Lexicon International.

11. Tikkanen R, Osborn R, Mossialos E, Djordjevic A, Wharton GA (2021) United States: Commonwealth Fund. The Commonwealth Fund, International Health Care System Profiles. 